\title{
Integer Linear Programming Approach to Scheduling Toll Booth Collectors Problem
}

\author{
Nordin Haji Mohamad ${ }^{1 *}$ and Fatimah Said ${ }^{2}$ \\ 'Institute of Mathematical Sciences, University of Malaya, 50603 Kuala Lumpur, Malaysia; nordinhm@um.edu.my \\ ${ }^{2}$ Faculty of Economics and Administration, University of Malaya, 50603 Kuala Lumpur, Malaysia; \\ fatimahs@um.edu.my
}

\begin{abstract}
A general daily staff scheduling problem with hourly requirement patterns is considered and formulated into an integer linear programming problem. A numerical illustrative example of scheduling toll booth collectors of full-timers and part-timers is presented and solved by LINDO.
\end{abstract}

Keywords: Integer Linear Program, Scheduling, Toll Booth Collectors.

\section{Introduction}

Linear programming is one of the widely recognized successes to emerge from operations research and management science. It is a well-developed and widely used tool for solving optimization problems. Its impact since the development of the simplex method in 1947 by George Dantzig has been extraordinary. Its ability to formulate and solve optimization problems has saved thousands or millions of dollars for most companies or businesses of even moderate size in the various industrialized countries of the world. Its use in other sectors as diverse as banking, education, forestry, petroleum and transportation is spreading rapidly. In a survey of Fortune 500 firms, $85 \%$ of respondents said that they had used linear programming. A survey of recent issues of the journal Interfaces published by INFORMS shows widespread applications of linear and integer programming in many different industries [8]. Other earlier applications are the popular product-mix problems [4], traditional make-buy problem [5], media advertisement selection [1], portfolio selection [27, 13, 16], machines scheduling and assignment $[2,28]$, multiperiod programming models [21, 24], tourism development [11], multi criteria model [19] and fuzzy model [12, 15].

* Corresponding author:

Nordin Haji Mohamad (nordinhm@um.edu.my)
One of the application-oriented linear programming problems is the personnel or workforce scheduling problem [17]. This encompasses two general problems: the daily scheduling problem where hourly work patterns are considered and the weekly scheduling problem where days off and days on work patterns are taken into account. In this paper we will address the former, the daily scheduling problem.

Certain facilities in many public systems operate around the clock seven days a week and face the problem of allocating manpower to meet the fluctuating hourly demand of the day. Some common examples are the demand for nursing personnel in hospitals, the demand for policemen on duty at each hour of the day and the staffing of fire protection units. Other frequently encountered examples include allocating of toll booth collectors at a toll plaza, check-out cashiers at a busy supermarket, bank tellers, telephone operators and as well as in manufacturing factories.

The main objective of staff scheduling problem is to determine the number of workforce that minimizes the total staffing costs while at the same time satisfies the staffing requirements for each hour or shift. If the cost per staff per unit time of shift is constant, the problem reduces to minimizing the total number of workforce. The emergence 
of many highways and toll plazas has transformed the operations of toll plazas and highway management into a booming economic activity generating millions of dollars a year. The schedule of toll booth collectors is one of the major components of its management strategies and merits academic attention. We will illustrate the integer linear programming (ILP) formulation of the problem by considering a typical daily staff scheduling problem of allocating toll booth collectors at a busy toll plaza which operates 24 hours a day, 7 days a week, and employs both full time and part time collectors.

\section{Literature Review}

A comprehensive survey of literature and studies on labour scheduling can be found in Bedworth and Bailey [6], Tien and Kamiyama [23] and Nanda and Browne [18]. Traditionally they are classified into three types. The first is the shift, or work time of the day, scheduling. Second is days-off or working days of the week scheduling. The third which combines the two types is known as tour scheduling. Jarrah et al. [10] uses an integer linear program and a heuristic method for solving manpower scheduling with working hours requirement of less than twenty-four hours on weekends. Billionnet [7] addresses the problem of scheduling employees with an integer linear program using a simple one-pass method. Lin et al. [14] study the workforce management system subject to 24 hours hotline service by utilizing the mixed integer linear program.

Thompson [22] introduces two integer programming models to describe shift scheduling viz a minimum acceptable service levels per period and a constraint on the average service level over the planning horizon. Atlason et al. [4] adjust Thompson's model for cases in which the service level is only obtainable by simulation. This allows for the calculation of the service level in a transient setting. Vohra [25] develops an expression for the minimum workforce size of the $(5,7)$ problem, in which each worker must work five days per week but only consecutive pairs of off days are allowed, in terms of daily labour demand. Ernst et al. [9] present an overview and the importance of the work schedule by using heuristic.

\section{Integer Linear Programming Formulation}

Staff scheduling or labour planning problem attempts to address staffing needs over a specific time period while minimizing its total daily personnel costs. Consider a single toll plaza which employs $F$ full-time toll booth collectors and part-timers to meet the hourly demand. Full-timers work from 9.00 am to $5.00 \mathrm{pm}$, and are allowed one hour lunch break between 11.00 am and $2.00 \mathrm{pm}$ such that at least $F_{0}$ of them are on duty during the lunch hour. A part-time employee, on the other hand, must put in exactly three continuous hours without any lunch benefit, and can start any time of the day (or night). Part-timers' earnings are subjected to a variable hourly wage rate while full-timers on average earn $c_{0}$ per day in salary and benefits. The management would like to determine a schedule that would minimize the total daily personnel costs while satisfying the hourly staff requirements.

\subsection{Problem Formulation}

Using a 24-hour time system, divide the daily operations into 24 time periods and let shift- $i$ denotes the work shift that begins at $i 00$ hour, $i=1,2, \ldots, 24$. Thus, shift- 1 corresponds to time period $0100-0200$ hour, ..., shift-10 corresponds to time period $1000-1100$ hour, ..., and so on. Further, let

$c_{i}=$ wage rate for shift $-i$,

$b_{i}=$ minimum number of collectors required for shift- $i$,

$P_{i}=$ number of part-timers beginning work on shift- $i$,

$F_{1}=$ number of full-timers having lunch break at $11.00 \mathrm{am}$,

$F_{2}=$ number of full-timers having lunch break at 12.00 noon, $F_{3}=$ number of full-timers having lunch break at $1.00 \mathrm{pm}$.

To help us formulate the problem we list all the information on part-timers and staff requirements pertaining to the problem as in Table 1. The problem can then be stated as

$$
\begin{aligned}
& \quad \operatorname{minimize} Z=c_{0} F+c_{1}\left(P_{1}+P_{23}+P_{24}\right)+c_{2}\left(P_{1}+P_{2}+P_{24}\right)+ \\
& \sum_{i=3}^{24} c_{i}\left(P_{i-2}+P_{i-1}+P_{i}\right) \\
& \quad \text { subject to }
\end{aligned}
$$

shift-1: $\quad P_{1}+P_{23}+P_{24} \geq b_{1}$,

shift-2: $\quad P_{1}+P_{2}+P_{24} \geq b_{2}$,

$P_{i-2}+P_{i-1}+P_{i} \geq b_{i}, \quad i=3, \ldots, 8,17, \ldots, 24$,

$P_{i-2}+P_{i-1}+P_{i}+F \geq b_{i}, \quad i=9,10,14,15,16$,

shift-11: $\quad P_{9}+P_{10}+P_{11}+F-F_{1} \geq b_{11}$,

shift-12: $\quad P_{10}+P_{11}+P_{12}+F-F_{2} \geq b_{12}$,

shift-13: $\quad P_{11}+P_{12}+P_{13}+F-F_{3} \geq b_{13}$,

$F-F_{1}-F_{2}-F_{3}=0$,

$F-F_{j} \geq F_{0}, j=1,2,3$,

$P_{i}, F, F_{j} \geq 0$ and integer, $i=1, \ldots, 24 ; j=1,2,3$.

The model comprises of 28 decision variables satisfying 28 constraints. The first three sets of constraints reflect the 
Table 1. Part-timers on duty in each shift

\begin{tabular}{|c|c|c|c|c|}
\hline Shift & Time period & Wage rate & Part-timers on duty & No. of collectors required \\
\hline 1 & $0100-0200$ & $c_{1}$ & $P_{1}, P_{23}, P_{24}$ & $b_{1}$ \\
\hline 2 & $0200-0300$ & $c_{2}$ & $P_{1}, P_{2}, P_{24}$ & $b_{2}$ \\
\hline 3 & $0300-0400$ & $c_{3}$ & $P_{1}, P_{2}, P_{3}$ & $b_{3}$ \\
\hline . & . & $\cdot$ & $\cdot$ & $\cdot$ \\
\hline . & . & . & . & . \\
\hline . & . & . & . & . \\
\hline $\mathrm{i}$ & $i 00-(i+1) 00$ & $c_{\mathrm{i}}$ & $P_{\mathrm{i}-2}, P_{\mathrm{i}-1}, P_{\mathrm{i}}$ & $b_{\mathrm{i}}$ \\
\hline$i+1$ & $(i+1) 00-(i+2) 00$ & $c_{\mathrm{i}+1}$ & $P_{\mathrm{i}-1}, P_{\mathrm{i}}, P_{\mathrm{i}+1}$ & $b_{i+1}$ \\
\hline$i+2$ & $(i+2) 00-(i+3) 00$ & $c_{i+2}$ & $P_{\mathrm{i}}, P_{\mathrm{i}+1}, P_{\mathrm{i}+2}$ & $b_{\mathrm{i}+2}$ \\
\hline . & . & $\cdot$ & $\cdot$ & $\cdot$ \\
\hline . & . & . & . & . \\
\hline . & . & . & . & . \\
\hline 22 & $2200-2300$ & $c_{22}$ & $P_{20}, P_{21}, P_{22}$ & $b_{22}$ \\
\hline 23 & $2300-2400$ & $c_{23}$ & $P_{21}, P_{22}, P_{23}$ & $b_{23}$ \\
\hline 24 & $2400-0100$ & $c_{24}^{23}$ & $P_{22}, P_{23}, P_{24}$ & $b_{24}^{23}$ \\
\hline
\end{tabular}

staffing requirements for work shifts from $5.00 \mathrm{pm}$ to 9.00 am the next day during which time no full-timer is engaged. The fourth constraint corresponds to the five time periods when all full-timers are on duty while the next three refer to the three scenarios during the three one-hour lunch breaks. The following constraint ensures that all full-timers enjoy their lunch break while the last set of constraints meets the requirement that at least $F_{0}$ full-timers are on duty during the lunch breaks. Finally all the decision variables must be non-negative integers.

\section{A Numerical Example}

To illustrate the formulation and solution of the problem, we consider a simple numerical example of scheduling toll booth collectors. The hourly wage rate $c_{i}$ and the staffing requirements $b_{i}$ for shift- $i,(i=1,2, \ldots, 24)$ are summarized in Table 2.

Suppose that the full-timers, on average earn USD50.00 per day in salary and benefits, and at least five full-timers must be on duty during the lunch break. The complete numerical integer linear programming problem can thus be stated as

minimize $Z=50 F+10\left(P_{1}+P_{2}+P_{3}+P_{4}+P_{5}\right)+15 P_{6}+$ $20\left(P_{7}+P_{8}\right)+15\left(P_{9}+P_{10}+P_{11}+P_{12}+P_{13}+P_{14}+P_{15}\right)+20$ $\left(P_{16}+P_{17}+P_{18}\right)+15\left(P_{19}+P_{20}\right)+10\left(P_{21}+P_{22}+P_{23}+P_{24}\right)$

subject to $\quad P_{1}+P_{23}+P_{24} \geq 2$

$$
P_{1}+P_{2}+P_{24} \geq 2
$$

$$
\begin{aligned}
& P_{1}+P_{2}+P_{3} \geq 2 \\
& P_{2}+P_{3}+P_{4} \geq 2 \\
& P_{3}+P_{4}+P_{5} \geq 2 \\
& P_{4}+P_{5}+P_{6} \geq 5 \\
& P_{5}+P_{6}+P_{7} \geq 15 \\
& P_{6}+P_{7}+P_{8} \geq 20 \\
& P_{7}+P_{8}+P_{9}+F \geq 20 \\
& P_{8}+P_{9}+P_{10}+F \geq 15 \\
& P_{9}+P_{10}+P_{11}+F-F_{1} \geq 10 \\
& P_{10}+P_{11}+P_{12}+F-F_{2} \geq 15 \\
& P_{11}+P_{12}+P_{13}+F-F_{3} \geq 15 \\
& P_{12}+P_{13}+P_{14}+F \geq 10 \\
& P_{13}+P_{14}+P_{15}+F \geq 10 \\
& P_{14}+P_{15}+P_{16}+F \geq 15 \\
& P_{15}+P_{16}+P_{17} \geq 20 \\
& P_{16}+P_{17}+P_{18} \geq 20 \\
& P_{17}+P_{18}+P_{19} \geq 10 \\
& P_{18}+P_{19}+P_{20} \geq 10 \\
& P_{19}+P_{20}+P_{21} \geq 5 \\
& P_{20}+P_{21}+P_{22} \geq 5 \\
& P_{21}+P_{22}+P_{23} \geq 5 \\
& P_{22}+P_{23}+P_{24} \geq 2 \\
& F-F_{1}-F_{2}-F_{3}=0 \\
& \quad F-F_{1} \geq 5 \\
& \quad F-F_{2} \geq 5 \\
& \quad F-F_{3} \geq 5 \\
& P_{\mathrm{i}}, F, F_{\mathrm{j}} \geq 0 \text { and integer, } i=1,2, \ldots, 24 ; j=1,2
\end{aligned}
$$


Table 2. Wage rate and number of staff required

\begin{tabular}{cccccc}
\hline Shift- $i$ & Wage rate (USD/hour) & No. of collectors required & Shift- $i$ & Wage rate (USD/hour) & No. of collectors required \\
\hline 1 & 10.00 & 2 & 13 & 15.00 & 15 \\
2 & 10.00 & 2 & 14 & 15.00 & 10 \\
3 & 10.00 & 2 & 15 & 15.00 & 10 \\
4 & 10.00 & 2 & 16 & 20.00 & 15 \\
5 & 10.00 & 2 & 17 & 20.00 & 20 \\
6 & 15.00 & 5 & 18 & 20.00 & 10 \\
7 & 20.00 & 15 & 19 & 15.00 & 10 \\
8 & 20.00 & 20 & 20 & 15.00 & 5 \\
9 & 15.00 & 20 & 21 & 10.00 & 5 \\
10 & 15.00 & 15 & 22 & 10.00 & 5 \\
12 & 15.00 & 10 & 23 & 10.00 & 2 \\
\hline
\end{tabular}

Table 3. Optimal staff scheduling problem

\begin{tabular}{|c|c|c|c|c|}
\hline Shift & $P_{\mathrm{i}}$ & $\begin{array}{l}\text { No. of collectors } \\
\text { on duty }\end{array}$ & $\begin{array}{l}\text { No. of collectors } \\
\text { required }\end{array}$ & $\begin{array}{l}\text { Excess } \\
\text { collectors }\end{array}$ \\
\hline 1 & 0 & 2 & 2 & 0 \\
\hline 2 & 2 & 2 & 2 & 0 \\
\hline 3 & 0 & 2 & 2 & 0 \\
\hline 4 & 0 & 2 & 2 & 0 \\
\hline 5 & 2 & 2 & 2 & 0 \\
\hline 6 & 8 & 10 & 5 & 5 \\
\hline 7 & 6 & 16 & 15 & 1 \\
\hline 8 & 6 & 20 & 20 & 0 \\
\hline 9 & 0 & 20 & 20 & 0 \\
\hline 10 & 1 & 15 & 15 & 0 \\
\hline 11 & 7 & 13 & 10 & 3 \\
\hline 12 & 2 & 15 & 15 & 0 \\
\hline 13 & 0 & 15 & 15 & 0 \\
\hline 14 & 0 & 10 & 10 & 0 \\
\hline 15 & 8 & 16 & 10 & 6 \\
\hline 16 & 10 & 26 & 15 & 11 \\
\hline 17 & 2 & 20 & 20 & 0 \\
\hline 18 & 8 & 20 & 20 & 0 \\
\hline 19 & 0 & 10 & 10 & 0 \\
\hline 20 & 2 & 10 & 10 & 0 \\
\hline 21 & 3 & 5 & 5 & 0 \\
\hline 22 & 0 & 5 & 5 & 0 \\
\hline 23 & 2 & 5 & 5 & 0 \\
\hline 24 & 0 & 2 & 2 & 0 \\
\hline
\end{tabular}

* Shifts $9-16$ include full-timers.

The problem is categorized as less than medium size problem and can be solved on a personal computer by most standard linear programming packages such as LINDO. The optimal solution generated suggests the employment of 77 collectors comprising of 69 part-timers and 8 full-timers such that 3 of them schedule their lunch break during the first and second hour respectively while the remainder two take the last lunch break ( $F=8$ with $F_{1}=3, F_{2}=3$ and $\left.F_{3}=2\right)$. The first group of two part-timers begin their daily shift at $2.00 \mathrm{am}\left(P_{2}=2\right)$ followed by the next two at $5.00 \mathrm{am}$ $\left(P_{5}=2\right)$ while the last batch of two part-timers clock in at $11.00 \mathrm{pm}\left(P_{23}=2\right)$. A summary of the optimal number of part-timers entering each shift and the number of collectors on duty during each shift is depicted in Table 3. The minimum total daily scheduling cost is USD 1550.00 .

A total of 28 part-timers were employed during the normal $9.00 \mathrm{am}-5.00 \mathrm{pm}$ working hours with an excess of 6 and 11 staff occurring during shift- 15 and shift- 16 respectively. These extra part-timers were employed to meet not only the current hourly demand but also the high demands of 20 collectors for the next two time periods in shift- 17 and shift-18 where there is no full-timer available.

Next, we solved the same problem but without the lunch hour restrictions. The optimal solution generated suggests that no full-timer should be considered $(F=0)$ and a total of 82 part-timers are scheduled to meet all the demands at a minimum total daily staff scheduling costs of USD1355.00 (a reduction of USD195.00). This is not surprising since part-timers are generally relatively cheaper than full-timers.

\section{Variations of the Problem}

This general 24-shift model with a time period of one hour per shift might not be appealing to most decision 
makers. Factories prefer operators to stay on for a longer shift. National security forces such as policemen and firemen are designated longer shift hours. The problem can be overcome either by allocating longer time periods for each shift or imposing a longer continuous working hour on each worker. A three hour-shift for organizations operating around the clock yields eight shifts per day, while those adopting 4 -shift system requires a time period of six hours per shift. The end result is a decrease in the number of shifts, and hence the number of decision variables and system constraints, thereby reducing the size and dimension of the problem and computational time.

Another aspect worth mentioning is that not all decision making units operate 24 hours a day. Banks [26], post offices [20], petrol stations, supermarkets, fast food outlets and government agencies providing counter services (for example The Road and Transport Department, and The Immigration Department) are some examples, to name just a few. The same model is still valid and can be applied by either assigning a very high unit cost or zero workforce for hours not in operation. This will also reduce the number of decision variables and system constraints, leading to a saving in computational time.

\section{Conclusion}

A general daily staff scheduling problem utilizing the 24-hour work shifts is proposed and illustrated by a numerical example of scheduling toll booth collectors to meet the fluctuating hourly demand of the day. The work force comprises both full-timers and part-timers. The integer linear programming problem formulated was successfully solved using LINDO.

Of no less importance is the weekly staff scheduling problem subjected to cyclic staffing requirements which involves the assignment of days off since each employee is entitled to some days off each week. This class of problem is commonly encountered in public services and merits further investigation.

\section{References}

1. Akarro R R J (2009). A linear programming model as an approximation for media advertisement selection on HIV/ AIDS spread in Dar es Salaam, Tanzania, European Journal of Scientific Research, vol 26(3), 417-429.

2. Aslan I (2011). A linear programming approach for different serial machines scheduling with optimizing batch size in a flow oriented synchronized production, 2011 International Conference on Innovation, Management and Service, IPEDR, vol 14(2011).

3. Atlason J, Epelman M A et al. (2004). Call center staffing with simulation and cutting plane methods, Annals of Operations Research, vol 127(1-4), 333-358.

4. Bahl H C, Taj S et al. (1991). A linear-programming model formulation for optimal product-mix decisions in materialrequirements-planning environments, International Journal of Production Research, vol 29(5), 1025-1034.

5. Baker K R, and Taylor R E (1979). A linear programming framework for cost allocation and external acquisition when reciprocal services exist, The Accounting Review, vol 54(4), 784-790.

6. Bedworth D D, and Bailey J E (1987). Integrated production control systems: Management, analysis, design, $2^{\text {nd }}$ Edn. Wiley, New York, 387-420.

7. Billionnet A (1999). Integer programming to schedule a hierarchical workforce with variable demands, European Journal of Operational Research, vol 114(1), 105-114.

8. Darby-Dowman K, and Wilson J M (2002). Developments in linear and integer programming, Journal of the ORS, vol 53(10), 1065-1071.

9. Ernst A T, Jiang H et al. (2004). Staff scheduling and rostering: A review of applications, method and models, European Journal of Operational Research, vol 153(1), 3-27.

10. Jarrah A I Z, Bard J F et al. (1994). Solving large-scale tour scheduling problem, Management Science, vol 40(9), 1124-1144.

11. Kottke M W (1987) Application of a linear programming model for estimating the economic impact of tourism development, Storrs Agricultural Experiment Station, Paper 28.

12. Lan Y, Lv X et al. (2007). A linear programming model of fuzzy portfolio selection problem, Proceedings of 2007 IEEE International Conference on Control and Automation, Guangzhou, CHINA.

13. Li Z, Wang S et al. (2000). A linear programming algorithm for optimal portfolio selection with transaction costs, International Journal of Systems Science, vol 31(1), 107-117.

14. Lin C K Y, Lai K F et al. (2000). Development of a workforce management system for a customer hotline service, Computer \& Operations Research, vol 27(10), 987-1004.

15. Liu H W (2011). Linear programming for portfolio selection based on fuzzy decision-making theory, Proceedings of The Tenth International Symposium on Operations Research and Its Applications (ISORA 2011), Dunhuang, CHINA.

16. Mansini R, Ogryczak W et al. (2003). On LP solvable models for portfolio selection, Informatica, vol 14(1), 37-62.

17. Miller H E (1976). Personnel scheduling in public systems: a survey, Socio-Economic Planning Science, vol 10(6), 241-249.

18. Nanda R, and Browne J (1992). Introduction to employee scheduling, Van Nostrand Reinhold, New York. 
19. Ogryczak W (2000). Multiple criteria linear programming model for portfolio selection, Annals of Operations Research, vol 97(1-4), 143-162.

20. Render B, and Stair R M (1997). Quantitative Analysis for Management. $6^{\text {th }}$ Edn, Prentice-Hall International Inc, USA.

21. Salmi T (1976). Multiperiod production and financial planning with two-stage linear programming, The Finnish Journal of Business Economics, vol 25(4), 454-476.

22. Thompson G M (1997). Labor staffing and scheduling models for controlling service levels, Naval Research Logistics, vol 44(8), 719-740.

23. Tien J M, and Kamiyama A (1982). On manpower scheduling algorithms, SIAM Review, vol 24(3), 257-287.
24. van Rensburg R J, and Bredenkamp B V (1997). Optimising nursery operation schedules with multiperiod linear programming, Southern African Forestry Journal, vol 179, 7-11.

25. Vohra R V (1987). The cost of consecutivity in the $(5,7)$ cyclic staffing problem, IIE Transactions. vol 19(3), 13-18.

26. Winston W L (1995). Introduction to Mathematical Programming: Applications and Algorithms, 2 ${ }^{\text {nd }}$ Edn., Duxbury Press, California, USA.

27. Young M R (1998). A minimax portfolio selection rule with linear programming solution, Management Science, vol 44(5), 673-683.

28. Zhang X, and Bard J F (2006). A multi-period machine assignment problem, European Journal of Operational Research, vol 170(2), 398-415. 